\title{
Gamma Tocopherol Measurement
}

National Cancer Institute

\section{Source}

National Cancer Institute. Gamma Tocopherol Measurement. NCI Thesaurus. Code C116211.

The determination of the amount of gamma tocopherol present in a sample. 